\title{
Synaptogenesis by Single Identified Neurons In Vitro: Contribution of Rapidly Transported and Newly Synthesized Proteins ${ }^{1}$
}

\author{
RICHARD T. AMBRON, ${ }^{2}$ HALINA DEN, AND SAMUEL SCHACHER
}

Departments of Anatomy and Cell Biology, and Psychiatry, and Center for Neurobiology and Behavior, College of Physicians and Surgeons, Columbia University and New York State Psychiatric Institute, New York, New York 10032

\begin{abstract}
The object of these studies is to define the molecular events that occur during synaptogenesis. Our approach is to use single identified Aplysia neurons grown in culture under conditions where chemical synapses are formed. In this report we studied synapses established by $\mathrm{R2}$, a giant cholinergic neuron, onto neurons R15 and L11, and a group of left upper quadrant (LUQ) cells. The detailed electrophysiology of these contacts was described in the preceding paper (Schacher, S., S. G. Rayport, and R. T. Ambron (1985) (J. Neurosci. 5: 2851-2856). Within the animal, $R 2$ synapses on thousands of unicellular mucus glands in the skin. R2 growing in vitro will establish contacts with isolated mucus glands. Although we do not know whether a functional synapse is formed, electron microscopy shows that the membrane in the area of contact is differentiated and that the ending is filled with various types of vesicles.

A single $\mathrm{R} 2$ regenerating neurites in vitro synthesizes more than 300 polypeptides containing $\left[{ }^{35}\right.$ S]methionine. Many of these are subsequently transported into the growing neurites. We compared the newly synthesized proteins made by R2 before and after synapse formation and found that the expression of a 68-kilodalton (kd) and 72-kd protein was markedly enhanced after synaptogenesis. The finding that only two proteins were affected implies that many of the proteins required for synapse formation are present in R2 prior to contacting a target cell. Support for this idea was obtained when we compared the proteins present in R2's neurites in vitro with those that are rapidly transported to R2's mature synapses in vivo (Ambron, R. T., S. Schacher, and S. G. Rayport (1985) J. Neurosci. 5: 2866-2873). Of the 28 transported proteins, one- and two-dimensional polyacrylamide gel electrophoresis showed that 25 were present in the neurites before $\mathrm{R} 2$ had contacted a target. This in vitro
\end{abstract}

Received October 8, 1984; Revised April 3, 1985;

Accepted April 10, 1985

${ }^{1}$ This research was supported by National Institutes of Health Grant NS 14555 and Career Development Award NS-00350 to R. T. A., National Institutes of Health Grant NS 19216 and National Science Foundation Grant 8215948 to S. S., and National Institutes of Health Grant GM 32099 which supports the mariculture tacility at the Marine Biological Laboratory (Woods Hole, MA). We wish to thank R. Wooley and M. Smedman for excellent technical assistance, T. Capo and S. Perritt for rearing the animals at Woods Hole, and Dr. M. Flaster for his comments and discussion of the manuscript.

${ }^{2}$ To whom correspondence should be addressed, at Department of Anatomy and Cell Biology, College of Physicians and Surgeons, Columbia University, 630 West 168th Street, New York, NY 10032. system therefore can be used as a model to dissect the molecular events underlying synaptogenesis.

Synaptogenesis between two neurons is a complex multi-step process that is initiated by growth cones and culminates in the formation of mature synapses. The focus of this and the accompanying papers (Schacher et al., 1985; Ambron et al., 1985) is to identify proteins that participate in this transformation. Studying the molecular events underlying synaptogenesis in vivo is difficult due to the complexity and heterogeneity of the nervous system. Consequently, we are using an in vitro system in which single identified neurons of Aplysia are grown under conditions where the formation of chemical synapses can be followed temporally and be assessed unequivocally by intracellular recording (Camardo et al., 1983). The same cell can then be evaluated either biochemically or morphologically, thereby ensuring that any observed changes are correlates of synapse formation. Although this is a regenerating system, it is likely that many of the processes that govern synaptogenesis during development in vivo are also utilized in vitro.

Neurons in culture have contributed greatly to our understanding of synapse development at the neuromuscular junction (Fischbach and Nelson, 1977; Hume et al., 1983), in autonomic ganglia (Patterson, 1978), and in dorsal root ganglia (Sonderegger et al., 1983). The formation of electrotonic synapses by regenerating invertebrate neurons (Bulloch et al., 1980; Bodmer et al., 1984) may also be useful in determining the factors that mediate interneuronal contacts.

The cell we have selected for our studies is R2, the giant cholinergic neuron of the abdominal ganglion. We chose R2 because its large size permits an analysis of newly synthesized proteins using only a single cell. In addition, there is a wealth of relevant information about this cell and its behavior. $R 2$ regulates mucus release from the skin and the ultrastructure of R2's synapses on the unicellular mucus glands has been described (Rayport et al., 1983). Moreover, R2's electrical properties and transmitter biochemistry have been defined (see Rayport et al., 1983, for references), several proteins and glycoproteins that appear destined for R2's terminals have been identified (Ambron, 1982; Ambron et al., 1985), and in a recent study (Drake and Lasek, 1984), the major cytoskeletal components of R2's cell soma and axons were characterized.

We have grown $\mathrm{R} 2$ in vitro either alone or in the presence of a neuron with which it will form transmitter-mediated synapses. R2 rapidly extends neurites in culture and synthesizes several hundred polypeptides when exposed to $\left[{ }^{35} \mathrm{~S}\right]$ methionine. We found that R2 growing in vitro in the absence of a target already has many of thie proteins that are transported to R2's mature synapses in vivo. After synapse formation, the expression of two proteins is markedly increased. These results imply that R2's neurites are capable of 
performing a variety of synaptic functions before synapse formation and are consistent with the finding of Hume et al. (1983) and Young and Poo (1983) that neurons in culture are able to synthesize and release neurotransmitter before contacting their target. We have also grown R2 with the unicellular mucus glands isolated from the skin. Neurites contacted the glands and invaginated into the cytoplasm to form a structure similar to the synapses R2 makes on the gland in vivo. These biochemical and morphological studies, when combined with the detailed electrophysiology of R2's synapses presented in the preceding paper (Schacher et al., 1985), indicate that this system may provide a means to dissect the various molecular events that occur during synaptogenesis between identified neurons.

\section{Materials and Methods}

Tissue culture procedures. The methods used for isolating and culturing the cells have been described in detail (Schacher and Proshansky, 1983). Abdominal ganglia from juvenile Aplysia (Marine Biological Laboratory, Woods Hole, MA) were bathed in protease. The sheath was removed and the individual cells were isolated from the ganglion using glass microelectrodes. In our experiments, each cell was removed with an initial segment of axon. The glial cells which surround the neuron in vivo are destroyed by the protease treatment R2, L11, R15, and left upper quadrant (LUQ) cells $L 2$ to
L6 were identified on the basis of size, position, and pigmentation (Koester and Kandel, 1977) and on the distribution of their axons (Schacher and Proshansky, 1983). Individual cells were transferred to poly-L-lysine-coated dishes containing $50 \%$ isotonic L-15 and $50 \%$ sterile Aplysia hemolymph. Neurons were allowed to adhere to the substratum for $24 \mathrm{hr}$ at room temperature. Thereafter, the cells were kept at $18^{\circ} \mathrm{C}$ and the medium was changed every 2 days. Intracellular recording was done with single-barrelled electrodes of 5 to 15 megohms filled with either $4 \mathrm{M}$ potassium acetate or $2.5 \mathrm{M}$ potassium chloride.

In some experiments the cells were plated in dishes containing $20 \mu \mathrm{M}$ anisomycin in order to assess the effect of inhibiting protein synthesis on neurite outgrowth (Schwartz et al., 1971; Ambron et al., 1975).

Protein labeling and gel electrophoresis. Neurons to be involved in synapse formation were grown in close proximity for 4 days to allow neurite extension and contact. The presence of synapses was then determined by intracellular recordings from both cells. Control neurons were grown in the same dish with the synapsing cells but were placed so that they would not contact any other neurons. If electrical recording showed that synapses were present, the neurons were metabolically labeled with 100 to $250 \mu \mathrm{Ci} / \mathrm{ml}$ of ${ }^{35}$ S]methionine (Amersham Corp., Arlington Heights, IL) for $24 \mathrm{hr}$ in hemolymph at $15^{\circ} \mathrm{C}$. After washing the dish three times, each neuron was removed, placed directly in SDS sample buffer, and heated at $70^{\circ} \mathrm{C}$ for $15 \mathrm{~min}$. In some experiments, R2's cell body was dissected from its neurites (Fig. 1) and both regions were analyzed separately. Labeling of R2's proteins in the isolated nervous system was as described in the following paper (Ambron
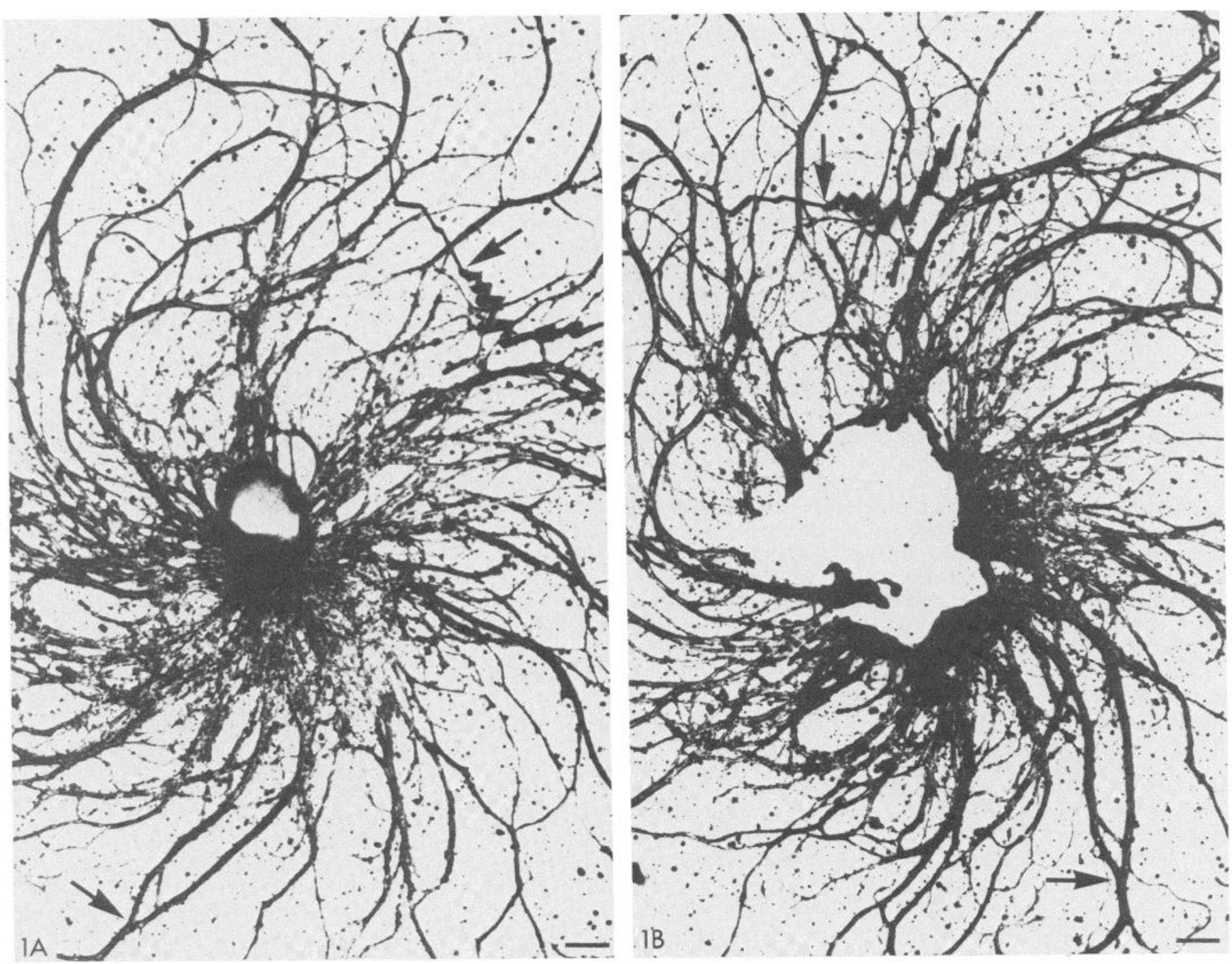

Figure 1. Separation of R2's cell body and neurites. R2's cell soma with a small segment of the proximal axon was removed from the ganglion. By 1 day the axon segment was resorbed and neurites began to emerge from the cell body. $A$, The cell after growth for 2 days; $B$, the same R2 neuron after the cell soma had been removed. Arrows serve as points of reference. Bar $=100 \mu \mathrm{m}$. 
et al., 1985). After incubation, R2's cell body was removed from the ganglion and dissected in iso-osmolar culture medium at $4^{\circ} \mathrm{C}$ to obtain cytoplasm free of glial cell contamination (Ambron, 1982).

Two-dimensional gel electrophoresis was by the method of O'Farrell (1975) as modified by Ames and Nikaido (1976). The ratio of Nonidet P-40 to SDS in the sample was adjusted to 8:1 just before electrophoresis. Isoelectric focusing gels contained $2 \% \mathrm{pH} 3.5$ to 10 and $0.5 \% \mathrm{pH} 5$ to 7 Ampholytes (LKB Instruments, Inc., Gaithersburg, MD). One-dimensional gel electrophoresis was carried out on either 5 to $15 \%$ linear gradient polyacrylamide slab gels or $7.5 \%$ slab gels using the discontinuous buffer system of Laemmli (1970). Gels were infiltrated with EnHance (New England Nuclear, Boston, MA) or sodium salicylate, and after drying, radioactive polypeptides were visualized by fluorography on Kodak X-AR film (Bonner and Laskey, 1974). Exposure was at $-80^{\circ} \mathrm{C}$ for from 3 days to 4 weeks.

Isolation of mucus glands. The viscera and all other internal structures were removed from juvenile animals and the body wall was pinned in a Sylgard-coated dish. The muscle layer was removed, and the skin was cut into small segments. One gram of tissue was added to $10 \mathrm{ml}$ of sterile Pucks solution containing $0.25 \%$ trypsin, $5 \mathrm{mg}$ of collagenase (Worthington Diag nostic Systems, Freehold, NJ), and 0.1 M HEPES buffer, $\mathrm{pH}$ 7.4. The mixture was incubated at $37^{\circ} \mathrm{C}$ for $30 \mathrm{~min}$. The digest was triturated, passed through a nylon mesh, and $10 \mathrm{mg}$ of pronase (Streptomyces Griseus; CalbiochemBehring Corp., La Jolla, CA) were added. After incubation at ambient temperature for $30 \mathrm{~min}$, the digest was centrifuged at low speed. The pellet was resuspended in hemolymph:L-15 (1:1) and added to a poly-L-lysinecoated Petri dish. The unicellular mucus glands could be identified by their selective staining with brilliant cresyl violet (Aldrich Chemical Co., Milwaukee, WI) which produces a dark blue color with mucus (Bang and Bang, 1972). Individual glands were removed and plated in a dish containing R2 cells that were growing neurites.

Electron microscopy. Tissue was fixed in $6 \%$ glutaraldehyde in S-collidine buffer $(\mathrm{pH} 7.4)$ containing $24 \%$ sucrose and $0.7 \mathrm{~mm} \mathrm{CaCl}$. After postfixation in osmium, the tissue was dehydrated and embedded in epoxy resin (Bailey et al., 1979). Sections of $90 \mathrm{~nm}$ were examined on a Phillips 300 electron microscope.

\section{Results}

The neuron $\mathrm{R} 2$ is able to establish chemical synapses with a variety of identified Aplysia neurons in vitro. In this study we have
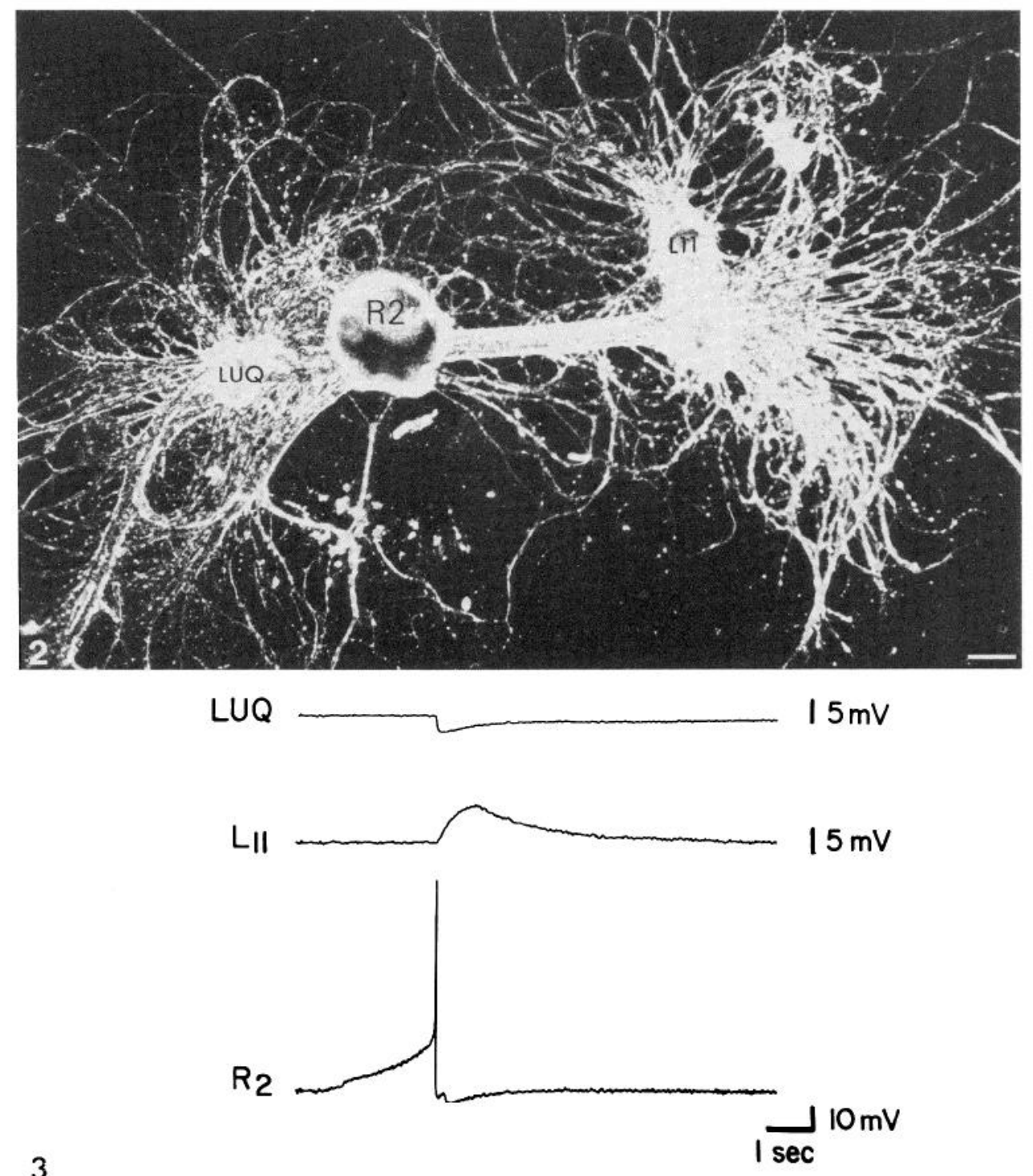

3

Figure 2. R2 forms transmitter-mediated synapses on neuron L11 and an LUQ cell. The neurons, removed from the ganglion with a long segment of proximal axon, were placed in close proximity in the culture dish. After 2 days of growth, neurites grew from the axon stumps and formed an overlapping network containing synapses (see Fig. 3). Bar $=100 \mu \mathrm{m}$.

Figure 3. Intracellular recordings from R2 synapsing onto L11 and an LUQ cell. The cells shown in Figure 2 were impaled with microelectrodes and were recorded from simultaneously. A single spike in R2 elicits an IPSP in the LUQ cell and a slow EPSP in neuron L11. L11 was hyperpolarized 10 mV from its resting potential (see Schacher et al., 1985, for the detailed electrophysiology of these connections). 
focused on synapses formed between R2 and neurons R15, L11, and a cluster of neurons (L2 to L6) found in the LUQ of the abdominal ganglion. When R2's cell body and those of the target neurons are placed in culture, the cells rapidly regenerate their neuritic processes. Each process contains a growth cone at its leading edge (Schacher and Proshansky, 1983). Neurite outgrowth is dependent on newly synthesized protein since, when the cells are grown in the presence of anisomycin, a potent inhibitor of protein synthesis, neurite extension ceases. By 4 days in vitro an overlapping neuritic network is formed (Fig. 2). The presence of chemical synapses in such a preparation can be determined unequivocally by stimulating $\mathrm{R} 2$ electrically and looking for a response in the follower cells (Fig. 3). R2 typically elicits an IPSP in LUQ neurons $(N=15)$, which is the appropriate response to acetylcholine in these cells. In contrast, R2 evokes a response in L11 that includes a slow excitatory component $(N=15)$. This is contrary to the response expected of a cholinergic input (Koester and Kandel, 1977). The detailed electrophysiology of R2's synapses is described in the preceding paper (Schacher et al., 1985).

Proteins synthesized by $R 2$ in vitro. R2's large size permits the analysis of newly synthesized proteins using only a single cell. To assess the biosynthetic capacity of R2 during regeneration, the cell was exposed to [ ${ }^{35} \mathrm{~S}$ ]methionine for $24 \mathrm{hr}$ during the period of neurite outgrowth. The cell body and neurites were then separated and the radiolabeled proteins were examined by two-dimensional polyacrylamide gel electrophoresis (PAGE) (see "Materials and Methods"). We find that a typical R2 cell soma synthesizes more than 300 distinct radioactive polypeptides (Fig. $4 A$ ). A considerable proportion of the methionine is incorporated into cytoskeletal proteins such as $\alpha$ - and $\beta$-tubulin, and actin. By $24 \mathrm{hr}$, these constituents have been transported by the slow phase of axonal transport into the neurites (Fig. 4B), where they presumably contribute to establishing and maintaining neuritic structure (Hoffman and Lasek, 1975). As expected, the labeling pattern of the neurites is less complex than that of the cell body, and at least 30 polypeptide species present in the soma are either absent or appear in greatly reduced amounts in the processes (Fig. 4B).

Changes in protein expression in R2 after synapse formation. The ability to grow R2 alone or under conditions where synapses are formed provides an opportunity to look for changes in the polypeptide composition after synaptogenesis. Comparison by onedimensional PAGE of newly synthesized proteins from nonsynapsing R2s and those $30 \mathrm{hr}$ after detection of synapses onto R15 or LUQ neurons failed to detect any differences. On two-dimensional gels, however, we found a 68-kilodalton ( $\mathrm{kd}$ ) and a 72-kd polypeptide the presence of which correlated with the formation of synapses (Fig. $5, a$ and $b$ ). Both proteins have the same isoelectrical point (6.7) and therefore may be related structurally. The $72-\mathrm{kd}$ protein was present in all seven experiments in which R2 had formed synapses but was absent from R2s that were growing alone. The 68-kd component was present in five of the synapsing R2s but was absent in the other two. Both were absent from control R2s that were growing in the same dish with the synapsing pairs. Interestingly, the higher molecular weight protein was not present when L10 formed synapses on LUQ neurons (Fig. 5c) and may therefore be specific to R2's synapses.

Next, we looked for the presence of the two proteins in vivo. After exposing R2 to $\left[{ }^{35}\right.$ S]methionine for $24 \mathrm{hr}$ in the isolated nervous system, the cell body was removed and dissected, and the cytoplasm was examined on gels (see "Materials and Methods"). As shown in Figure $5 d$, both proteins were present.

Presynaptic proteins are present in R2's regenerating neurites. The failure to find major changes in R2's polypeptide pattern by 30 $\mathrm{hr}$ after synaptogenesis suggested that many of the proteins required for synapse formation might be present in R2's neurites prior to contact with target neurons. In experiments reported in the following paper (Ambron et al., 1985), we identified 28 proteins that were destined for R2's presynaptic terminals on mucus glands in the skin.

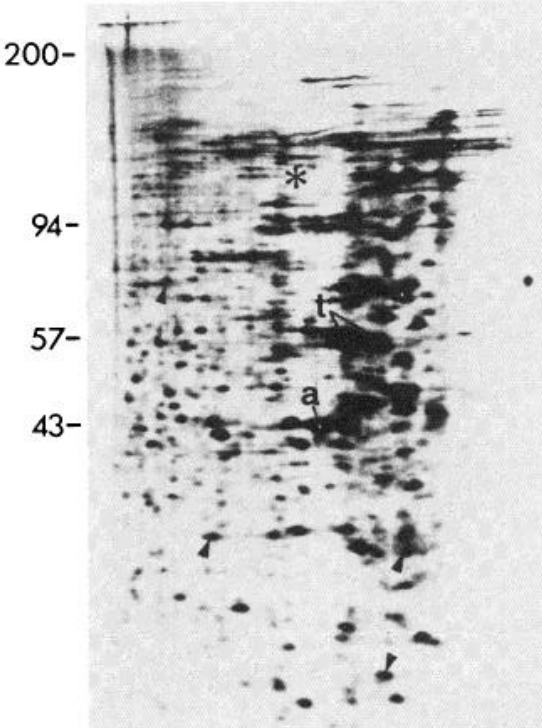

4A

Figure 4. Two-dimensional SDS-PAGE of R2's newly synthesized proteins in vitro and in vivo. A, Fluorograph of radiolabeled polypeptides from R2's cell soma. Isoelectric focusing $(\mathrm{pH} 7.0$ to 4.5$)$ was carried out with the acid end on the right. The cell was grown in vitro for 2 days and exposed to [ ${ }^{35} \mathrm{~S}$ ] methionine for $24 \mathrm{hr}$, and the cell body was then separated from the neurites. $t$ and $a$ indicate the positions of the tubulins and actin, respectively. Arrowheads point to some of the more than 30 proteins in the cell soma that are absent or present in markedly reduced amounts in the neurites. $B$, Fluorograph of the radiolabeled polypeptides from the neurites of the same cell. C, Radiolabeled polypeptides rapidly transported toward R2's synapses in vivo (see Ambron et al., 1985). Arrows serve to facilitate a comparison with fluorograph B. All of the transported proteins are found in R2's cell body and neurites in vitro except the 110-kd component denoted by an asterisk in $B$ and $C$. One of the proteins migrates just below tubulin and another migrates below actin (see also Fig. 6). Several transported proteins did not enter the focusing gel. 


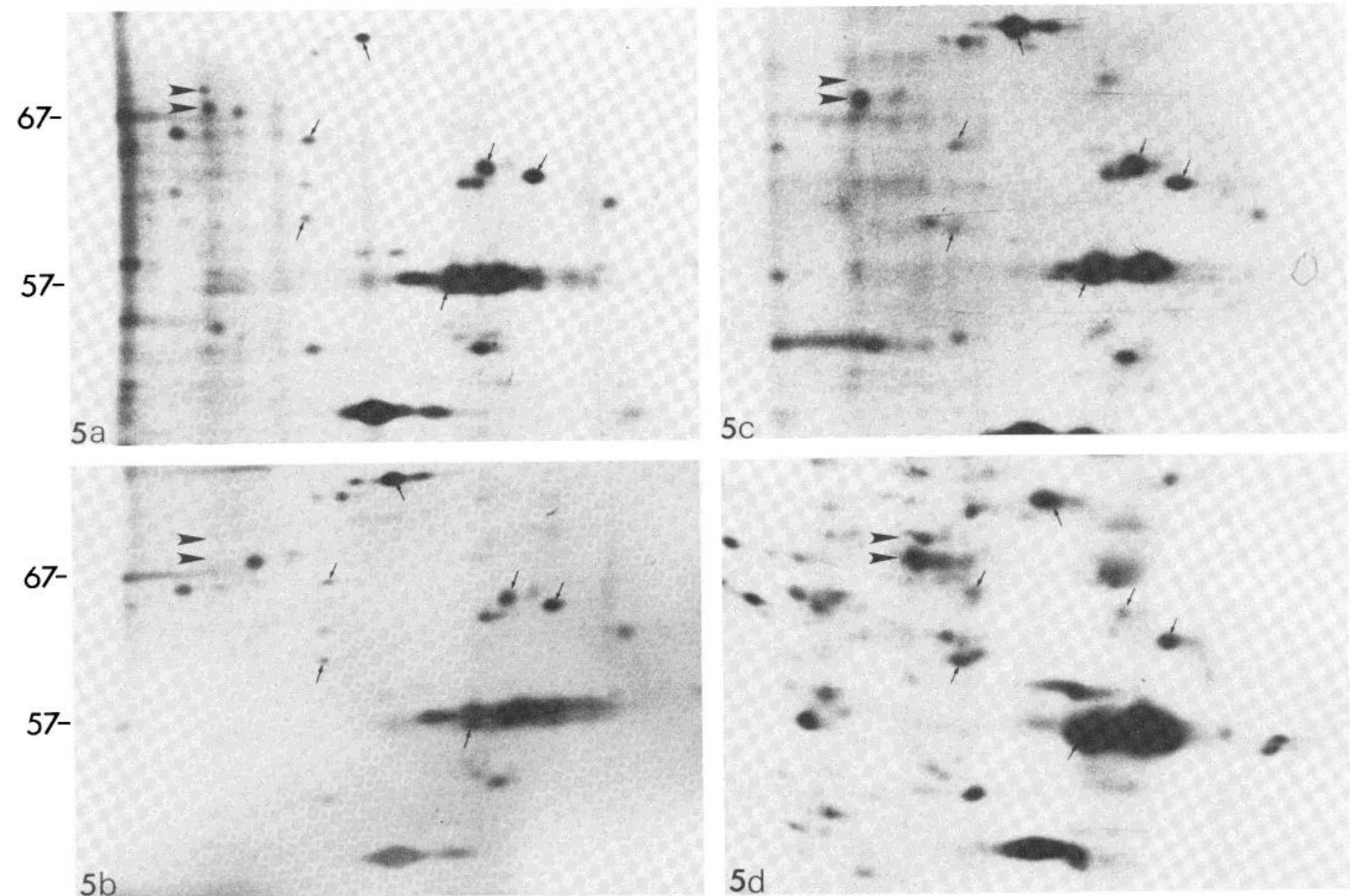

Figure 5. Two-dimensional SDS-PAGE showing the expression of newly synthesized radiolabeled proteins after synaptogenesis. Only a portion of each fluorograph is shown. a, Proteins in R2's cell soma $30 \mathrm{hr}$ after intracellular recording showed the presence of synapses onto LUQ cells. Arrowheads refer to polypeptides, the presence of which correlates with functional synapses. Arrows point to common proteins to be used for comparison of the gels. $b$, Proteins in a control R2 grown in the same dish as the cell in $a$, but at a distance from any other cells. Note the absence of the two polypeptides. Both cells were exposed to the same $\left[{ }^{35} \mathrm{~S}\right]$ methionine, and the proteins were collected, electrophoresed, and detected by fluorography under identical conditions. c, Proteins made by neuron L10 synapsing on LUQ cells. Only one of the polypeptides is present. d, Proteins from R2's cytoplasm in vivo. Both polypeptides are present. The spots are more diffuse than in the other experiments due to the high ionic strength of the medium used to dissect R2's cell body (see "Materials and Methods").

When these proteins were compared on one-dimensional gels with the proteins in R2's neurites, 25 of the 28 were present (Fig. 6). One of the missing components is a 110-kd membrane glycoprotein that is prominent in the transported fraction (Fig. 6, arrow). A protein of approximately the same molecular weight appears as a streak (Fig. $4 C$, asterisk) on two-dimensional gels of the transported material and again appears to be missing from the neurites (Fig. 4B). Several proteins on the one-dimensional gels do not appear on our twodimensional gels, probably because they have isoelectric points outside the range of our isoelectric focusing gels.

Evidence for synaptic membrane specialization. We have characterized the electrophysiological events at R2's synapses (Schacher et al., 1985) and have identified a number of proteins that are likely to participate in synaptogenesis. We next asked, What is the morphological correlate of synapse formation in vitro? Unfortunately, the complexity of the interlacing neurites of R2, R15, and LUQ cells makes it an unfavorable preparation to locate and study the structure of the synaptic connections. We can, however, use the unicellular mucous glands isolated from the skin as R2's target. Isolated glands and those in the skin appear similar (Fig. 7) except that we could not find remnants of morphologically identifiable synaptic endings in serial sections through isolated glands. When $\mathrm{R} 2$ was placed in culture with the glands, neurites invaginated into the glandular cytoplasm (Fig. 8, top), forming a contact similar to that seen in vivo (Rayport et al., 1983). The invaginated membrane acquires a dense coating, and various types of vesicles accumulate (Fig. 8, bottom). Although we do not know whether a functional synapse is formed because we have not succeeded in recording from the glands, the micrographs show that organelles in the region of the invagination are organized differently than they are in other areas of contact between the neurites and gland.

\section{Discussion}

The formation of chemically mediated synapses is the culmination of a complex series of molecular events. At a minimum, synaptogenesis can be divided into stages involving contact, recognition, stabilization, and, finally, maintenance. The molecules that mediate these fundamental processes are only beginning to be identified (Estridge and Bunge, 1978; Edelman, 1983; Pfenninger et al., 1983; Reichardt and Kelly, 1983). Knowledge of the role of individual components is central to understanding how an integrated nervous system is elaborated during development. In this report we describe studies using single identified neurons of Aplysia that begin to address these issues.

Identified neurons $R 2$ and $L 10$ in vitro: Contrast in synaptic specificity. The neuron R2 is one of a pair of giant cells that innervate mucous glands in the skin (Rayport et al., 1983). R2's isolated cell body will form chemical synapses with identified neurons L11 and 


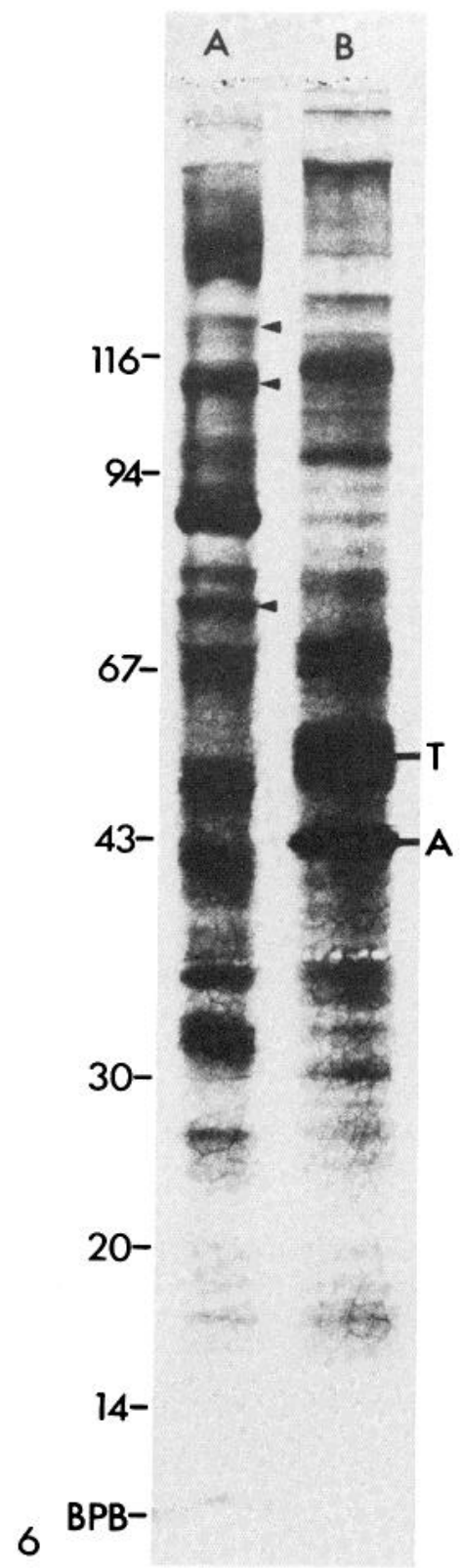

Figure 6. Comparison of radiolabeled proteins rapidly transported in vivo with those present in R2's neurites in vitro. Fluorograph after SDS 5 to $15 \%$ linear gradient PAGE. A, Proteins rapidly transported to R2's synapses in vivo. $B$, Proteins present in R2's neurites in vitro. Arrowheads denote three major transported proteins that do not appear in the neurites. $A$, actin; $T$, tubulin; $B P B$, bromophenol blue. Note that the transported fraction contains a band that migrates just below tubulin and another just beneath actin.

R15, and LUQ cells (Fig. 2 and Schacher et al., 1985) in vitro. Our criterion for the formation of a synapse is rigorous and requires that stimulation of R2 elicit a response in the follower cell (Fig. 3). Since R2 is not known to synapse on neurons in the animal (Rayport et al., 1983), synapses onto L11, and so on, must be considered novel or inappropriate. Other invertebrate neurons also make novel synapses in vitro, but the majority of these are electrical (Bulloch et al., 1980; Bodmer et al., 1984).

It is important to contrast the behavior of R2 in vitro with that of identified neuron L10. This neuron has numerous follower cells in vivo but, unlike $\mathrm{R} 2$, forms synapses in culture only with its normal targets (Camardo et al., 1983). R2 and L10 also differ in the response that they elicit in their synaptic partners: L10 always elicits the proper cholinergic response (Camardo et al., 1983), whereas R2 evokes both cholinergic and noncholinergic responses, depending upon the follower cell. We do not believe that the differences in the behavior of the two cells are artifacts of culture conditions but, rather, that they reflect innate differences in synaptic potentiality (see Schacher et al., 1985, for additional discussion).

Changes in protein expression in R2 during synapse formation. $R 2$ regenerating in culture transports many newly synthesized polypeptides into the growing neurites (Fig. 4). Included among these are cytoskeletal components as well as proteins destined to be incorporated into the surface membrane. Since regenerating neurites respond to the iontophoretic application of neurotransmitter and engage in synapse formation, their membranes must contain at least some proteins characteristic of pre- or postsynaptic terminals. The question is, how many such proteins are present? Put another way, is a regenerating neurite capable of forming a functional synapse immediately upon contacting a target, or is it necessary that a large number of additional proteins be synthesized and transported to the nascent presynaptic terminal?

Our data suggest that few qualitative changes in protein synthesis occur within $30 \mathrm{hr}$ after synapses are detected by electrophysiological recordings. We examined more than $20 \mathrm{R} 2$ neurons before and after synapsing on LUQ cells. No differences could be detected on high resolution gradient slab gels. Only after we used two-dimensional PAGE were we able to detect two radiolabeled proteins of $M_{\mathrm{r}}$ $=68,000$ and 72,000 , the presence of which correlated uniquely with synapse formation (Fig. 5). So far, we have found these components in R2's cell body both in vivo and after synapsing on LUQ cells in vitro. It is not known whether they are transported from the cell body.

Care was taken in these experiments to exclude interference by extraneous factors. Both the R2 destined to form synapses and the R2 control were placed in the same dish: they were exposed to the same hemolymph for an equal amount of time and were labeled with the same methionine. Thus, both cells would be exposed to any trophic substances that might be released from the growing targets and which might influence the presynaptic cell independent of synapse formation.

Our results showing minimal changes in protein expression must be interpreted with caution since it is likely that the labeling protocol detects only a portion of the total polypeptide species being made: changes in the synthesis of less abundant species might be missed. However, by labeling the cells soon after synapse formation, we would expect to maximize the chances of detecting those proteins synthesized in response to synaptic contact. Sonderegger et al. (1983) also reported finding relatively few biosynthetic changes in dorsal root ganglion cells after they synapsed on spinal neurons.

Proteins transported to R2's mature synapses in vivo are present during growth in vitro. The failure to find extensive changes in the pattern of protein synthesis after synaptogenesis implies that R2's growth cones and mature synapses have proteins in common. To examine this issue, we identified 28 polypeptides that are rapidly transported to R2's synapses in vivo (Ambron et al., 1985). When these were compared with the proteins in R2's neurites, 25 of the 28 were present (Figs. 4 and 6). How many of these actually arrive at the growth cone remains an open question. The protein composition of growth cones is only beginning to be examined (Pfenninger et al., 1983). Although it is not yet feasible to isolate growth cones from R2, right upper quadrant (RUQ) cells from the Aplysia abdominal ganglion have remarkably large growth cones $(30 \mu \mathrm{m}$ in diameter) that can be isolated in pure form (Flaster et al., 1984; M. S. Flaster, S. Schacher, and R. T. Ambron, manuscript in preparation). Preliminary comparisons between proteins in R2's neurites and those in isolated RUQ cell growth cones show at least seven components in common. A rigorous demonstration that the rapidly transported proteins are present at R2's growth cones would support the idea 

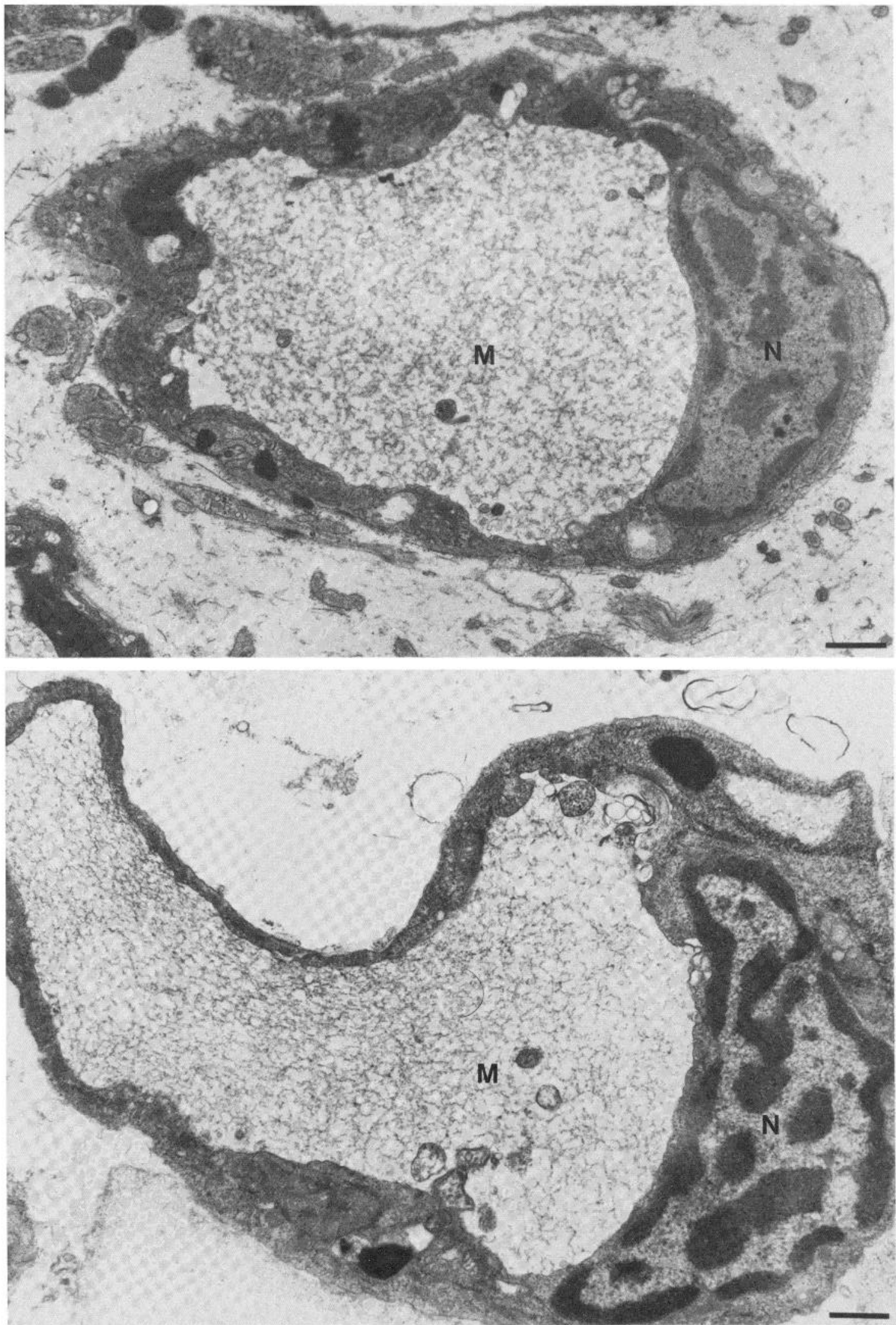

Figure 7. Morphology of R2's target unicellular mucus glands before and after isolation. Top, Single gland cell in situ. The neck of the gland projects to the exterior of the body wall which is on the left. The nucleus $(N)$ is at the base of the cell and the secretory material $(M)$ occupies a large central vacuole. Bottom, An isolated mucus gland maintained in vitro. Notice the similarity in size and general morphology to the gland in situ above. Bar $=3 \mu \mathrm{m}$. 

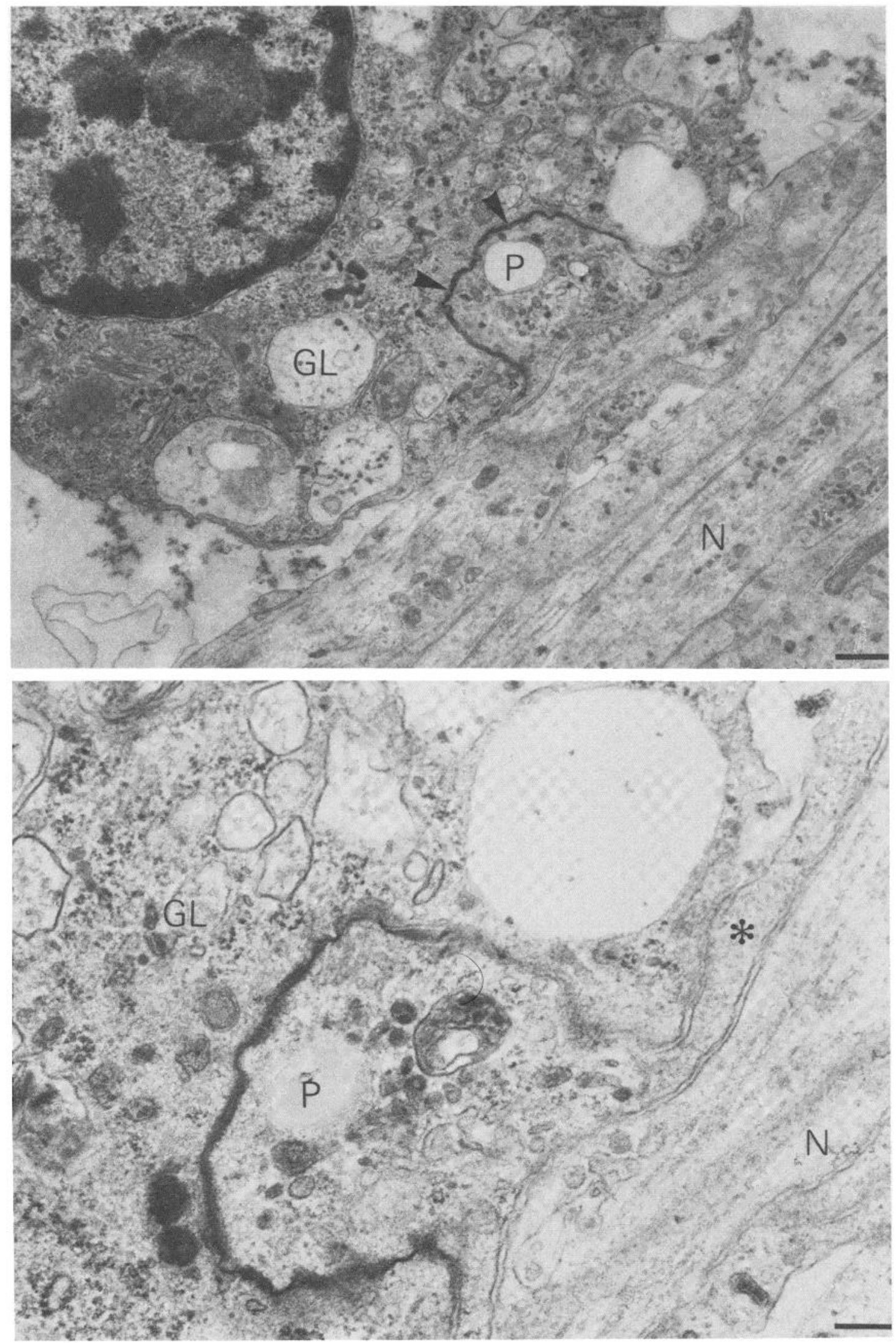

Figure 8. Ultrastructure of R2's contact on individual mucus glands in vitro. R2 was grown in culture for 1 day and then isolated glands were added. Five days later the cells were fixed, serial-sectioned, and examined by electron microscopy. Top, A process $(P)$ from R2's outermost neurite has invaginated into the gland $(G L)$ forming a structure that contains vesicles of various sizes as well as a dense deposit in the region of the opposing membranes (arrowheads). The nucleus of the gland is in the upper left corner. Other neurites (for example, $N$ ) containing mainly microtubules and fibrous elements are seen in passage. Bar $=0.4 \mu \mathrm{m}$. Bottom, An adjacent section viewed at higher magnification. Notice that the dense membrane exists only in the region of the invagination. The neurite giving rise to the invagination is indicated by an asterisk. An adjacent neurite $(N)$ shows no evidence of specialization. Bar $=0.2$ $\mu \mathrm{m}$. 
that these structures are primed for synapse formation. Work by Hume et al. (1983) and Young and Poo (1983) has already shown that growth cones of neurons growing in vitro can synthesize, mobilize, and release acetylcholine upon stimulation, functions generally ascribed to mature presynaptic endings.

That R2 is capable of forming morphologically differentiated contacts on its targets in vitro is indicated by its interaction with the mucus glands (Fig. 8). Thus, R2's growth cone undergoes changes in membrane organization during a time when the expression of relatively few proteins is enhanced (see above). Conversely, we expected that several proteins would disappear during the period after synaptogenesis: it is reasonable to assume that the elaborate motility apparatus (Letourneau, 1982) as well as components involved in pathfinding (Raper et al., 1983) would cease being synthesized once a synapse is established. Our failure to observe the disappearance of polypeptides suggests that many of these are put to alternative uses in the mature synapse. Alternatively, the time course for the transition from growth cone to presynaptic ending may be slow, and it may require more time after the initiation of chemical transmission for other changes in protein expression to be detected.

\section{References}

Ambron, R. T. (1982) Differences in the distribution of specific glycoproteins among the regions of a single identified neuron. Brain Res 239: 489-505.

Ambron, R. T., J. E. Goldman, and J. H. Schwartz (1975) Effect of inhibiting protein synthesis on axonal transport of membrane glycoproteins in an identified neuron of Aplysia. Brain Res. 94: 307-323.

Ambron, R. T., S. Schacher, and S. G. Rayport (1985) Proteins rapidly transported to the synapse of a single identified neuron of Aplysia californica. J. Neurosci. 5: 2866-2873.

Ames, G. and K. Nikaido (1976) Two dimensional gel electrophoresis of membrane proteins. Biochemistry 15: 616-623.

Bailey, C. H., V. F. Castellucci, J. Koester, and E. R. Kandel (1979) Cellular studies of peripheral neurons in siphon skin of Aplysia californica. J. Neurophysiol. 42: 530-557.

Bang, B. G., and F. B. Bang (1972) Preparation of urn cells. Am. J. Pathol. 68: 407-417.

Bodmer, R., D. Dagan, and I. B. Levitan (1984) Chemical and electrotonic connections between Aplysia neurons in primary culture. J. Neurosci. 4: 228-233.

Bonner, W. M., and R. A. Laskey (1974) A film detection method for tritium labeled proteins and nucleic acids in polyacrylamide gels. Eur. J. Biochem 46: 83-88.

Bulloch, A. G. M., S. B. Kater, and A. D. Murphy (1980) Connectivity changes in an isolated molluscan ganglion during in vivo culture. J. Neurobiol. 11: $531-546$.

Camardo, J., E. Proshansky, and S. Schacher (1983) Identified Aplysia neurons form specific chemical synapses in culture. J. Neurosci 3: 26142620.
Drake, P. F., and R. J. Lasek (1984) Regional differences in the neuronal cytoskeleton. J. Neurosci. 4: 1173-1186.

Edelman, G. M. (1983) Cell adhesion molecules. Science 219: 450-457.

Estridge, M., and R. Bunge (1978) Compositional analysis of growing axons from rat synapthetic neurons. J. Cell Biol. 79: 138-155.

Fishbach, G. D., and P. G. Nelson (1977) Cell culture in neurobiology. in Handbook of Physiology. Section 1: The Nervous System, J. M. Brookhart and V. B. Mountcastle, pp. 719-774, American Physiological Society, Bethesda, MD

Flaster, M. S., S. Schacher, and R. T. Ambron (1984) Biochemical characterization of growth cones of identified neurons cultured in vitro. Soc. Neurosci. Abstr. 10: 923.

Hoffman, P. N., and R. J. Lasek (1975) The slow component of axonal transport. Identification of major structural polypeptides of the axon and their generality among mammalian neurons. J. Cell Biol. 66: 351-366.

Hume, R. I., L. W. Role, and G. D. Fischbach (1983) Nature 305: 632-634.

Koester, J., and E. R. Kandel (1977) Further identification of neurons in the abdominal ganglion of Aplysia using behavioral criteria. Brain Res. 121: $1-20$

Laemmli, V. K. (1970) Cleavage of structural proteins during the assembly of the head of bacterophage T4. Nature 277: 680-685.

Letourneau, P. C. (1982) Nerve fiber growth and its regulation by extrinsic factors. In Neuronal Development, N. C. Spitzer, ed., pp. 213-254, Plenum Press, New York.

O'Farrell, P. H. (1975) High resolution two-dimensional gel electrophoresis of proteins. J. Biol. Chem. 250: 4007-4021.

Patterson, P. H. (1978) Environmental determination of autonomic neurotransmitter functions. Annu. Rev. Neurosci. 1: 1-17.

Pfenninger, K. H., L. Ellis, M. P. Johnson, L. B. Friedman, and S. Somlo (1983) Nerve growth cones isolated from fetal rat brain: Subcellular fractionation and characterization. Cell 35: 573-584.

Raper, J. A., M. J. Bastoni, and C. S. Goodman (1983) Guidance of neuronal growth cones: Selective fasiculation in the grasshopper embryo. Cold Spring Harbor Symp. Quant. Biol. 48: 587-598.

Rayport, S. G., R. T. Ambron, and J. Babiarz (1983) Identified neurons R2 and LPI, control mucus release in Aplysia. J. Neurophysiol. 49: 864-876.

Reichardt, L. F., and R. B. Kelly (1983) A molecular description of nerve terminal function. Annu. Rev. Biochem. 82: 871-926.

Schacher, S., and E. Proshansky (1983) Neurite regeneration by Aplysia neurons in dissociated cell culture: Modulation by Aplysia hemolymph and the presence of the initial axonal segment. J. Neurosci. 3: 2403-2413.

Schacher, S., S. G. Rayport, and R. T. Ambron (1985) Giant Aplysia neuron R2 reliably forms strong chemical connections in vitro. J. Neurosci. 5: $2851-2856$.

Schwartz, J. H., V. F. Castelucci, and E. R. Kandel (1971) Functioning of identified neurons and synapses in abdominal ganglion of Aplysia in absence of protein synthesis. J. Neurophysiol. 34: 939-953.

Sonderegger, P., M. C. Fishman, H. C. Bauer, and P. G. Nelson (1983) Axonal proteins of presynaptic neurons during synaptogenesis. Science 221: 1294-1297.

Young, S. H., and M-m. Poo (1983) Spontaneous release of transmitter from growth-conos of embryonic ncurons. Nature 305: 634-637. 